\title{
We Are Americans Now, We Live in the Tundra
}

Today in hazy San Francisco, I face seaward

Toward China, a giant begonia-

Pink, fragrant, bitten

By verdigris and insects. I sing her

A blues song; even a Chinese girl gets the blues, Her reticence is black and blue.

Let's sing about the extinct

Bengal tigers, about giant Pandas-

"Ling Ling loves Xing Xing ... yet,

We will not mate. We are

Not impotent, we are important.

We blame the environment, we blame the zoo!"

What shall we plant for the future?

Bamboo, sasagrass, coconut palms? No!

legumes, wheat, maize, old swines

To milk the new.

We are Americans now, we live in the tundra

Of the logical, a sea of cities, a wood of cars.

Farewell my ancestors:

Hirsute Taoists, failed scholars, farewell

My wetnurse who feared and loathed the Catholics, Who called out:

Now that the half-men have occupied Canton Hide your daughters, lock your doors! 